\title{
Preface
}

A Natural History of Human Morality is a companion volume to my 2014 book A Natural History of Human Thinking. The parallel titles are appropriate because in both volumes I propose the same two-step sequence in the evolution of human social life: first, new forms of collaborative activity, and then new forms of cultural organization. In the first volume I attempted to spell out the species-unique kinds of thinking that emerged from these new forms of social life. In the current volume I attempt to explicate how these new forms of social life structured the way that early humans came to engage in moral acts that either subordinated or treated as equal their own interests and the interests of others, even feeling a sense of obligation to do so. This moral attitude or stance did not—and still does not—win out consistently in individuals' actual decision making, of course, but it does make those decisions, whatever their outcome, moral decisions.

I have been gathering my thoughts for this volume over the past five years or so, beginning with a seminar on the evolution of human cooperation held in the fall of 2009 here at the Max Planck Institute for Evolutionary Anthropology, and continuing with a similar seminar on the evolution of human morality held in the winter of 20I2-2013. Many interesting and 
fruitful discussions in those seminars have shaped my thinking on these issues significantly, and I thank all of those who participated. I also had a number of very useful discussions during this same time period with Sebastian Rödl, who helped me with some difficult philosophical concepts.

In addition, a number of people read and provided very useful commentary on earlier versions of the manuscript. In particular, one or another draft version was read by Ivan Cabrera, Robert Hepach, Patricia Kanngiesser, Christian Kietzmann, Berislav Marusic, Cathal O’Madagain, and Marco Schmidt. I thank them all for their extremely helpful comments and suggestions. I would like to single out for special thanks Neil Roughley and Jan Engelmann, who engaged with me and the manuscript especially deeply and on multiple occasions. For certain, the manuscript is much more coherent for all of their insights. I also thank Andrew Kinney, Richard Joyce, and an anonymous reviewer from Harvard University Press for their comments on the manuscript as well.

Finally, as with the first volume, my deepest gratitude goes to Rita Svetlova, with whom I have discussed extensively all of the most important ideas in this volume-and others that she helped me to let go of - to the great benefit of the final product. I dedicate this book to her and our children. 


\section{A Natural History of Human Morality}


